\title{
Application of Data Science in China's Sustainable Agriculture System
}

\author{
Qiyuan, Liu, ${ }^{1}$ \\ ${ }^{1}$ Ningbo Foreign Language School, Ningbo, Zhejiang 315121, China
}

\begin{abstract}
The presented article focuses on demonstrating the application of data science and its prospect in China's agriculture system. Applying machine learning in atmospheric science, data scientists could recreate the historical data, building relationships between the available data and the relative predictors. Therefore, inputting the relative variables like climate data, wind, and pollution, scientists could forecast the incoming weather and accurately predict the future yield. Moreover, data science helps farmers detect the soil quality, seeking for feasible ways to improve it. Thus, Data science is of great practical significance to the sustainable development and stable high yield of China's agricultural system.
\end{abstract}

\section{Introduction}

While experiencing rapid populace development, China has dealt with nourishment safety and food quality a long time [1]. To bargain with the expanding request for nourishment, the Chinese agrarian segment received the philosophy of "pollute first and then clean up" [2]. However, this method solves only gain short-term benefits, but irreversibly hurts land's sustainability and conducts severe pollution in the long run [3]. The acute utilization of fertilizer and chemicals would corrupt the accessible arable soil, inevitably harming the Chinese rural industry and cutting the worldwide nourishment to a remarkable degree [1]. Therefore, a useful tool for promoting the arable land's sustainability and keeping high production is needed.

Fortunately, the need for "sustainable agriculture" has been widely considered in the recent 20 years, with different analysts proposing innovation as an arrangement to deal with such a critical slant over the top utilization of chemical fertilizers. It is conceivable and commendable to see into the sort of innovation that would offer assistance the agriculturists oversee their cultivating hones within the most effective way, subsequently fortifies the maintainable horticulture of China [4].

Data science, such an innovation, exists much obliged to the Fourth Mechanical Insurgency that involved the fast improvement of populace and computing, catering to the tremendous food request and maintainable farming framework [5]. Through the vast amounts of information, data science combines measurement knowledge in science to get crucial data and related trends, including information handling, analyzing, and determining amid the cultivation [6]. It makes a difference in individuals to analyze the accessible information of any kind and foresee the significant drift. Such a prescient capacity of information is adopted to optimize results in different areas extending from Fund to Natural Science. In this study, we investigate the employ of data science and the method to employ in agriculture through its prediction in weather, yield, and capability to improve the soil quality.

\section{Data Science's application in agriculture}

\subsection{Weather prediction}

Climate plays a vital part in farming generation and impacts the development, improvement, and surrender of crops. Climate variations can cause physical harm to crops and soil disintegration. The quality of crops from the field to advertise depends on the climate [7]. For instance, agribusiness is directly linked with climatic conditions since agriculture depends on climate estimating to arrange for when to plant, water, and gather. With the help of data science, businesses can work with more accuracy without disruptions [8]. Collecting and analyzing the data, Information science specialists know how to utilize apparatuses that distinguish the designs and connections that will something else be covered up. They can draw conclusions that thrust agricultural science forward through examining particular variables driving to alter in climate. The discoveries brought around by filtering through databases and ponders to conclude things like this in rural forms can bring around surprising changes.

Firstly, advanced models and Machine learning are utilized to estimate the climate employing a combination of physical models and measured Information on tremendous computer frameworks (Table 1). Then, it is fundamental to have the correct Information to be near to perfect choices. The Information ought to be taken

*Corresponding author e-mail: qy.liu@ protonmail.com 
concerning the location and the time at which it is famous should be considered. After being processed, weather data enables farmers to predict floods and natural disasters. This requires collecting Information, just like the encompassing street condition and the precipitation of the region that year. One extends giving Rice ranchers in Taiwan Web of things sensors to accumulate primary data around their crops. The Information will go into a database to assist ranchers in optimizing their generation cycles, indeed in case climate alter makes the assignment significantly troublesome. Due to climate alteration,

\begin{tabular}{llll}
\multicolumn{3}{c}{ Table 1 The application of different methods of data science in the agriculture system } \\
\hline $\begin{array}{l}\text { Data } \\
\text { Science }\end{array}$ & Method & Advantages & Deficiencies \\
\hline \multirow{3}{*}{ Weather } & Machine & For farmers, & Weather is unstable and usually \\
Prediction & Predictive & avoiding & fluctuates in certain areas \\
& Modeling & lossecessary under & \\
& & extreme weather.
\end{tabular}

\begin{tabular}{|c|c|c|c|}
\hline \multirow{7}{*}{$\begin{array}{l}\text { Yield } \\
\text { Prediction }\end{array}$} & \multirow{2}{*}{$\begin{array}{l}\text { Self Organizing } \\
\text { Map models }\end{array}$} & \multirow{7}{*}{$\begin{array}{l}\text { Currently, the } \\
\text { actual yield is } \\
\text { close to the } \\
\text { predicted one, } \\
\text { enabling farmers } \\
\text { to deploy the } \\
\text { planting and } \\
\text { harvesting. }\end{array}$} & Overly relying on the past data. \\
\hline & & & Weathers are not \\
\hline & Actual & & predicted. \\
\hline & Predictive graph & & \\
\hline & & & \\
\hline & & & \\
\hline & & & \\
\hline \multirow{7}{*}{$\begin{array}{l}\text { Soil } \\
\text { Quality }\end{array}$} & Satellite imagery & Recommending & \multirow{7}{*}{$\begin{array}{l}\text { The improvement of the soil } \\
\text { quality itself is unnoticeable. }\end{array}$} \\
\hline & Sensor Data & farmers with & \\
\hline & & appropriate & \\
\hline & & fertilizer. & \\
\hline & & Identifying the & \\
\hline & & proper types of & \\
\hline & & $\begin{array}{l}\text { soil on certain } \\
\text { land. }\end{array}$ & \\
\hline
\end{tabular}

\subsection{Yield Prediction}

Data science is also a unique tool to meet the needs of the agricultural industry. Computers can necessarily learn the arrangement of data, interpret complex data, and work out reasonable rules in combination with previous algorithms [11]. In agriculture, the estimation and prediction of crop yields are particularly vital because they enable farmers to develop crops most efficiently and conveniently. Similarly, thanks to high-performance computing innovations, machines have fast learning and computing power. Use the images from the data integration to observe the cultivated land and input the images with the characteristics of the crops into the computer, Information about soil and crops is then synthesized to predict yields [12]. Data science permits the agriculturists to reenact different cultivating strategies on the computer and select the one that is likely to deliver the principal sum of generation.

Abdicate forecast in exactness cultivating, is considered of great significance for the enhancement of taking after the traditional agricultural calendar is now not enough. However, information investigation may alter agribusiness's long run until the end of time [9].

However, climate determining may be an exceptionally troublesome work. Machine learning algorithms can offer assistance to anticipate what will happen within the brief term. In order to attain the way better comes about, the hysteresis highlight or RNN structure ought to be utilized within the neural arrangement [10]. 
weather data, precipitation, and pollution might enhance the model's predictions.

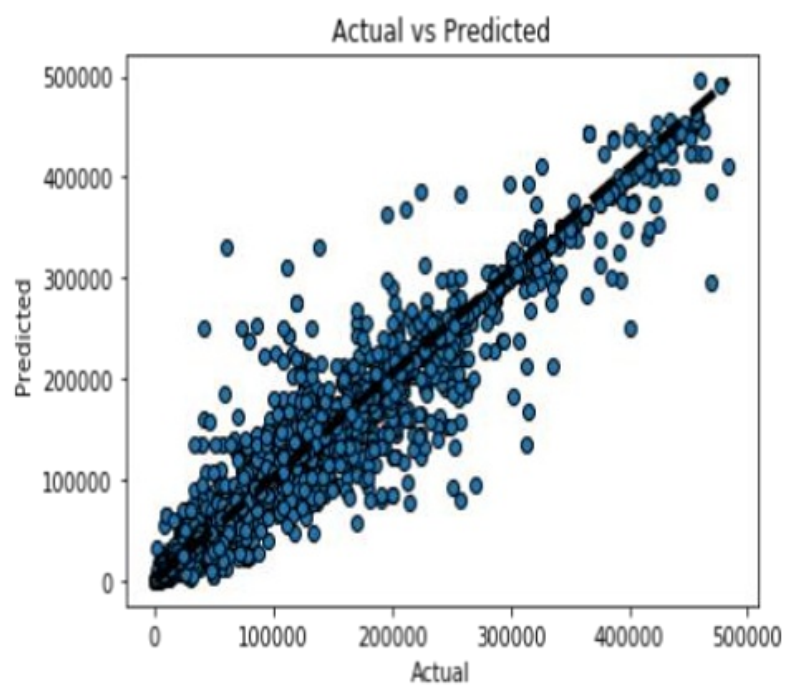

Figure 1. The relationship between the actual yields and the predicted yield [14].

\subsection{Soil Quality}

The quality of arable land is also crucial during the planting. In Egypt, agriculturists utilize water pumps to gather water from the stream Nile to their crops. Progressed water sprinklers are used to inundate expansive areas, and this helps the crops to urge sufficient water, which is essential in their development. This strategy is valuable within the productive utilization of water. Moreover, researchers scrutinize agrarian soil information to make strides their understanding of how soil contributes to climate alter through the discharge of nursery gasses and how soil information can offer assistance adjust to climate change. Gathering such data is dubious, but researchers accept it may fill crevices in Information approximately the relationship between soil and climate alter [9].

As of now, a few ranges in China depend on satellitebased soil and edit observing to examine zones more rapidly than conventional strategies permit. This makes a difference in choosing what crops ought to be developed on a specific piece of arrival. It spares a parcel of time and exertion and comes about in higher surrender generation. Soil administration is a critical portion of maintainable horticulture since the quality of the soil generally decides the abdicate. Ranchers must subsequently oversee their soil successfully by watering it legitimately [15]. Data science is pivotal during the planting because it may bolster "soil drying, temperature," and dampness substance [13]. In a soil drying test, through precipitation data, the computer anticipated the soil drying, helping the soil administration handle by educating the agriculturists around when and "how much water to put" [16]. All the time, fertilizer manhandle could be a worldwide phenomenon due to the complexity of finding the "most excellent fertilizer." Most farmers still depend on trial and mistake, mystery, and estimation. As a result, crops do not reach their abdicate potential and increment natural contamination. Currently, data scientists are able to exhort agriculturists with the correct amount of fertilizers.

\section{Conclusion}

This article summarizes the application of data science in weather prediction, yield prediction, and soil quality in China's sustainable agriculture system. Adopting machine learning and inputting relevant climate data, scientists could accurately predict the yield and future weather. With satellite imagery and sensor data, data science professionals could deeper understand the quality of soil digitally, recommending more suitable fertilizer more improve the soil quality. Noticeably, data is the future, and increasingly information exists, so increasingly decisions can be made utilizing it. Data science gives the ranchers with surrender expectations and soil quality, making a difference in them to alter their cultivating practices accordingly. Therefore, to achieve a more sustainable agriculture system with high productivity, more emphasis, and employ data science during the planting is needed. Innovation has played a considerable part in creating this industry. Nowadays, it is conceivable to develop crops in a leave by utilizing of agrarian biotechnology, and there is much more scope within the future.

\section{References}

1. National Bureau of Statistics of China. Communique on Major Data of the Second National Agricultural Census of China. (2008)

2. Liu X. Feeding China's Growing Needs For Grain. Nature. (2010).

3. $\mathrm{Yu} \mathrm{J}, \mathrm{Wu}$ J. The Sustainability of Agriculture Development in China: The AgricultureEnvironment Nexus. Sustainability. (2018).

4. Liu J. China's Road to Sustainability. Science. (2010).

5. Schwab K. The Fourth Industrial Revolution: What It Means, How to Respond. World Economic Forum. (2016). 
6. Dhar V. Data Science and Prediction. Communications of the ACM. (2013).

7. DATAFLAIR TEAM. (2019). Data Science in Agriculture - Advancing Together \& Benefiting Farmers. Data Flair.

8. DATAFLAIR TEAM. Data Science for Weather Prediction - The Prerequisite to all Natural Disasters. Data Flair. (2019).

9. Matthew K. 6 Ways the Agricultural Industry Is Benefiting From Data Scientists. Toward Data Science. (2019).

10. Shchur A. Weather forecasting with data science approaches. Towards Data Science. 2019.

11. Gautam A. (2019). Data Science in Agriculture. Trends in Data Science.

12. Pantazi X., Moshou D., Alexandridis T., Whetton R., Mouazen A. (2016). Wheat Yield Prediction Using Machine Learning and advanced Sensing Techniques. Science Direct.

13. Pantazi X., Moshou D., Alexandridis T., Whetton R., Mouazen A. Wheat Yield Prediction Using Machine Learning and advanced Sensing Techniques. Science Direct. (2016).

14. Almahdi H. Predicting Crops Yield: Machine Learning Nanodegree Capstone Project. Towards Data Science.

15. Montgomery M. The Urban Transformation of the Developing World. Science. (2008).

16. Coopersmith E., Minsker B., Wenzel C., Gilmore B. Machine learning assessment of myocardial ischemia using angiography: Development and retrospective validation. Science Direct. (2014). 